
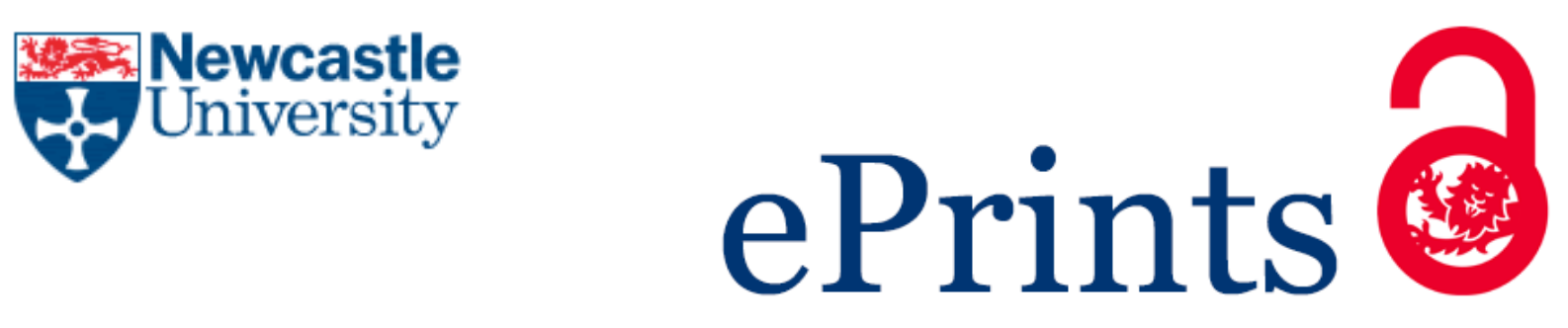

Han Z, Sani B, Akkanen J, Abel S, Nybom I, Karapanagioti H, Werner D. A Critical Evaluation of Magnetic Activated Carbon's Potential for the Remediation of Sediment Impacted by Polycyclic Aromatic Hydrocarbons. Journal of Hazardous Materials 2015, 286, 41-47.

\title{
Copyright:
}

(C) 2014. This manuscript version is made available under the CC-BY-NC-ND 4.0 license

DOI link to article:

http://dx.doi.org/10.1016/i.jhazmat.2014.12.030

Date deposited:

$18 / 09 / 2015$

Embargo release date:

19 December 2016

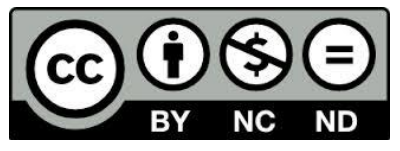

This work is licensed under a

Creative Commons Attribution-NonCommercial-NoDerivatives 4.0 International licence 


\section{A Critical Evaluation of Magnetic Activated Carbon's Potential for the Remediation of Sediment Impacted by Polycyclic Aromatic Hydrocarbons}

ZHANTAO HAN ${ }^{a, b, c}$, BADRUDDEEN SANI ${ }^{\mathrm{a}}, J A R K K O A K K A N E N^{d}$, SEBASTIAN ABEL ${ }^{d}, I N N A$ NYBOM ${ }^{d}$, HRISSI K. KARAPANAGIOTI ${ }^{e}$, and DAVID WERNER ${ }^{a, *}$

${ }^{a}$ School of Civil Engineering and Geosciences, Newcastle University, Newcastle upon Tyne, NE1 7RU, England, United Kingdom

${ }^{b}$ Institute of Hydrogeology and Environmental Geology, Chinese Academy of Geological Sciences, Shijiazhuang, 050061, China

${ }^{c}$ Hebei Key Laboratory of Groundwater Remediation, Shijiazhuang, 050061, China

${ }^{\mathrm{d}}$ Department of Biology, University of Eastern Finland (UEF), P.O. Box 111,

FI-80101 Joensuu, Finland

e Department of Chemistry, University of Patras, 26500 Patras, Greece

* Corresponding author phone: 0044191222 5099; fax: 00441912226502

E-mail: david.werner@ncl.ac.uk.

KEYWORDS PAHs; Sediment remediation; Magnetic Activated Carbon; Ecotoxicity 


\section{Introduction}

Numerous laboratory studies and several field studies have demonstrated significant reductions in the chemical and biological availability of PCBs [1-6], PAHs [7-10] and DDT [11] following addition of activated carbon (AC) to polluted soils or sediments. The amendment of just a few percent by weight $\mathrm{AC}$ has been shown to reduce the available concentration of these contaminants, in many cases by more than 90\% [12-14]. However, the amended AC cannot be readily retrieved from the soil and sediment matrix, and may in some instances induce adverse ecological responses [15-17], as was observed in one fifth of the 82 studies reviewed by Janssen and Beckingham [18]. Also, concerns that the sorbent-bound pollutants may be released back into the environment in response to future environmental changes, if the pollutant-loaded sorbent materials remain in place, motivate research into sorbent recovery methods. Current research directions include the sieving out of granular activated carbon (GAC) from finer sediment [19], and the use of activated carbon felt [20]. A potential disadvantage of the sieving method is that millimetre sized GAC is a less effective sorbent amendment than finer sized AC particles $[11,21]$ due to the AC size and particle number dependant pollutant mass transfer kinetics in mixed [22] and even more so in unmixed sediment [23]. A potential disadvantage of the AC felt method is that it would be difficult to achieve a good AC felt distribution within the sediment. Good AC distribution is also crucially important for amendment effectiveness, especially under field conditions [6].

Magnetic activated carbon (MAC) [24] and magnetic biochar (MBC) [25] recovery is not dependant on the particle shape or size, and magnetic sorbent recovery methods are already being used largescale in the water and mining industries [26]. The aim of this study was therefore to explore the idea of using MAC or MBC for sediment remediation. To the best of our knowledge, this is the first investigation of the potential feasibility of using MAC or MBC for sediment remediation.

\section{Materials and Methods}

\subsection{Sediment Characterization}

Sediment was obtained from the intertidal zone of the Rivers Wear, at South Hylton, and Tyne, at Gateshead, Newcastle upon Tyne, UK. A very detailed geochemical characterization of these sediments has been previously published [27]. The solid adsorbed PAHs of the sediment were extracted by accelerated solvent extraction (ASE) using hexane:acetone (pesticide grade from SigmaAldrich, St. Louis, US) 50:50 v:v to determine the solid phase PAH concentrations. Free aqueous PAH concentrations were determined by using polyethylene (PE) passive samplers. Passive samplers were produced by cutting $26 \mu \mathrm{m}$ thick PE plastic bags (VWR International Ltd., Leicestershire, UK) into small pieces $(0.15 \pm 0.01 \mathrm{~g})$ which were cleaned with hexane:acetone 80:20 v:v for $24 \mathrm{~h}$. PAHs [28] and PCBs [29] sorption by PE passive samplers has been previously characterized. More details of solid phase and PE PAHs extraction and analysis are provided as Supporting Information (page 2).

\subsection{Preparation of magnetic $A C$ and biochar}

Two kinds of AC were used for the MAC synthesis, one produced from anthracite coal by Calgon (Calgon Filtrasorb 400) obtained from Chemviron (Lancashire, United Kingdom), and one produced from Coconut shell and obtained from Norit (Amersfoort, The Netherlands). Two kinds of biochar were obtained from Romchar, Harghita, Romania, and Oxford Biochar Ltd., Dorset, United Kingdom. The producer labeled the later biochar as "organic". These sorbents were labeled as CoalAC, CocoAC, Bio and OrgBio, respectively and ground with a ceramic mortar to achieve a size distribution $<64 \mu \mathrm{m}$, the size of powdered activated carbon. 
CoalAC, CocoAC, Bio and OrgBio were magnetized by a wet precipitation technique based on a previously published technique [24, 30], with a few modifications. Briefly, $2.5 \mathrm{~g}$ activated carbon or biochar, $1.83 \mathrm{~g} \mathrm{FeSO}_{4} \cdot 7 \mathrm{H}_{2} \mathrm{O}$ and $3.33 \mathrm{~g} \mathrm{FeCl}_{3} \cdot 6 \mathrm{H}_{2} \mathrm{O}$, and $100 \mathrm{~mL}$ of de-ionized water were combined in a beaker. The mixtures were heated to $65^{\circ} \mathrm{C}$ and then cooled to below $40^{\circ} \mathrm{C}$ while stirring using magnetic stir bars. A $5 \mathrm{M} \mathrm{NaOH}$ solution was added into the mixtures drop-wise to raise the $\mathrm{pH}$ to 10-11 and precipitate the iron hydroxides. The mixtures were stirred for an hour and then left to settle overnight. The precipitate-laden sorbents were washed with deionized water, rinsed with ethanol, and dried at $80^{\circ} \mathrm{C}$ overnight. These dried composite materials were then washed into a beaker and the magnetic activated carbon or biochar particles were collected with magnetic rods and dried again at $80^{\circ} \mathrm{C}$ overnight. The magnetic carbon materials were labeled as MagCocoAC, MagCoalAC, MagBio, and MagOrgBio, respectively. The specific surface area (SSA) of the samples were determined by gas $\left(\mathrm{N}_{2}\right)$ adsorption/desorption with the Micromeritics TriStar 3000 Analyzer system using the Brunauer, Emmett, and Teller (BET) equation. Isotherms with 30 adsorption and 20 desorption points were conducted at liquid nitrogen temperature $(77 \mathrm{~K})$.

\subsection{Determination of activated carbon-water partitioning coefficient $\left(K_{A C}\right)$ for PAHs}

PE samplers $(0.15 \pm 0.01 \mathrm{~g})$ were preloaded with PAHs and sediment organic matter by exposing them to sediment for 7 weeks. Previous studies showed that equilibrium of PAHs between PE and water is established with 10 hours [31]. Then the PE samplers were collected from the sediment, rinsed with deionized water, wiped clean with lab tissue, and each was placed into a $10 \mathrm{~mL}$ vial sealed with screw cap with aluminum lining. $20 \mathrm{mg} \mathrm{AC,} \mathrm{BC,} \mathrm{MAC} \mathrm{or} \mathrm{MBC,} 0.18 \mathrm{~mL}$ of $1 \% \mathrm{NaN}_{3}$ and $9 \mathrm{~mL}$ of deionized (DI) water was added into each vial and vials were prepared in triplicate. Triplicate controls without carbon were also set up for clean PE samplers and pre-loaded PE samplers. These vials were placed on a rotary shaker at $130 \mathrm{rpm}$. One month later, the PE samplers were taken out and wiped clean for PAHs extraction and analysis by GC-MS. Sorbent-water partitioning coefficients were obtained for each sorbent via a mass-balance. More details of this method are provided by Hale and Werner [23].

\subsection{Comparing the sediment remediation potential of different sorbent materials}

A preliminary batch test was conducted to compare the sediment remediation potential of all the AC, $\mathrm{BC}, \mathrm{MAC}$ and MBC. $5 \mathrm{~g}$ dry River Wear sediment were combined with $157 \mathrm{mg} \mathrm{AC}$ or BC, $250 \mathrm{mg}$ MAC or MBC (produced from $157 \mathrm{mg} \mathrm{AC} \mathrm{or} \mathrm{BC),} \mathrm{one} \mathrm{PE} \mathrm{sampler}(0.15 \pm 0.01 \mathrm{~g})$ and $35 \mathrm{~mL}$ deionized water in $40 \mathrm{~mL}$ glass vials, sealed with Teflon-lined screw caps and shaken on a rotary shaker at 110 rpm. Blank samples without sorbent amendment were also prepared. All samples were prepared in triplicate. One month later, the PE samplers were taken out and wiped clean for PAH extraction and analysis by GC-MS. Remediation performance was assessed by comparing the reductions in PE sampler uptake of PAHs as compared to sediment without sorbent amendment. More details of this method are provided by Hale and Werner [23].

\subsection{Sediment remediation with carbon and magnetic carbon amendment}

For a more detailed sediment remediation trial, three quota of $245.9 \mathrm{~g}$ ( $94.6 \mathrm{~g}$ dry weight) River Tyne sediment were put into 3 wide mouth amber glass jars, and $4.75 \mathrm{~g}$ CoalAC or $7.65 \mathrm{~g}$ MagCoalAC (produced from $4.75 \mathrm{~g}$ CoalAC, equal to $5 \%$ and $8.1 \%$ of the unamended dry sediment weight) were added into one of the jars, respectively. Three pre-cleaned PE samplers were put into each jar, and the 
bottles were sealed with caps and shaken on horizontal shaker at $110 \mathrm{rpm}$. After 3 months, PE samplers were recovered, wiped cleaned, and extracted for PAH analysis, and MagCoalAC was then recovered from the sediment using a magnetic rod, and cleaned with deionized water and dried to determine MAC recovery. $9 \mathrm{~g}$ dry sediment from each bottle was extracted by ASE for PAHs analysis. Three clean PE samplers were then added into each bottle again and shaken to monitor an eventual rebound of available PAHs in the jar from which MAC had been recovered. After 4, 5, and 6 months, the PE samplers were thus replaced with clean ones, wiped cleaned and extracted for PAH analysis. After 6 months, $9 \mathrm{~g}$ dry sediment from each bottle was again extracted by ASE for PAHs analysis.

\subsection{Characterization of the recovered magnetic carbon}

The mineral composition of the pristine and recovered magnetic carbon and biochar were characterized by X-ray powder diffraction (XRD). The XRD instrument is a PANalytical X'Pert Pro MPD, powered by a Philips PW3040/60 X-ray generator and fitted with an X'Celerator detector. Diffraction data is acquired by exposing powder samples to $\mathrm{Cu}-\mathrm{K} \alpha \mathrm{X}$-ray radiation. Continuous scan XRD data were collected at diffraction angles between $10^{\circ}$ and $90^{\circ}$ operating at $40 \mathrm{~mA}$ and $40 \mathrm{kV}$. The step scan was conducted with the step width $0.033^{\circ}$ and counting time of $10 \mathrm{~s}$.

The particle shapes and surface element distribution were measured by Scanning Electron Microscope equipped with an EDX detector (SEM, Leo 1450 VP, Oxford INCA Energy 200Premium Si (Li) SATW-Detector). The samples were prepared by dry deposition of the carbon particles on conductive, sticky carbon pad, coating with $8 \mathrm{~nm}$ carbon. The coating of the carbon was to prevent the accumulation of static electricity during SEM-EDX analysis. Carbon coating can also avoid the interference of EDX spectrum usually caused by gold coating.

\subsection{Test of ecotoxicity of the AC amended and MAC amended sediment}

After 6 months treatment, the unamended, AC amended and MAC amended sediment after MAC recovery were tested for their ecotoxicity. Egestion rate, growth and reproduction of Lumbriculus variegatus were used as endpoints in order to examine the ecologic effects of the sorbent amendments. Experimental microcosms were set up as triplicates in $200 \mathrm{ml}$ glass jars filled with $50 \mathrm{~g}$ (wet weight) of amended sediments and $130 \mathrm{~mL}$ of overlying artificial freshwater (hardness: $1 \mathrm{mM} \mathrm{Ca}+\mathrm{Mg}$ ). According to a method developed by Leppänen and Kukkonen [32], a thin layer of white quartz grains (diameter $1.0-1.5 \mathrm{~mm}$ ) was applied on top of the sediment in order to spatially separate the egested fecal pellets from the sediment and allow their collection with a transfer pipette. A number of 10 worms (acclimatized overnight in artificial freshwater) was introduced to each replicate and exposed to the sediment for 28 days. Fecal pellets were collected on days 2, 4, 7, 21 and 28 of the experiment, dried at $105{ }^{\circ} \mathrm{C}$ overnight and weighed using a fine scale (Denver Instrument SI-234, Bohemia, NY, USA). At the end of the exposure time the test organisms were sieved out of the sediment using a $200 \mu \mathrm{m}$ sieve and transferred to artificial freshwater and left for $6 \mathrm{~h}$ of depuration time to empty their guts. The worms were counted to assess the reproduction rate and weighed using a microbalance (Sartorius 4503 Micro, Göttingen, Germany). The growth rate was determined as the change in biomass (wet weight) over the exposure time. A more detail method description can be found in Nybom et al. [16]. 


\section{Results and Discussion}

\subsection{Magnetic sorbent synthesis and characterization}

MACs and MBCs were successfully produced from the four carbonaceous materials. XRD analysis shown in Fig. 1 for MagCoalAC as an example confirmed that the iron oxides deposited on the carbon matrices were mainly magnetite or maghemite. These minerals cannot be readily distinguished by their XRD spectra, but both minerals have strong magnetism. MACs and MBCs could be readily recovered from aqueous solution with a magnetic rod.

The specific surface areas (SSA) of pristine carbon and magnetic carbon are provided in Table 1. The SSA of CoalAC, CocoAC and Bio were reduced following magnetization, while that of OrgBio was enhanced. The increase of SSA for OrgBio might be attributed to the dissolution of calcium carbonate deposits in pores during the magnetite impregnation process, as indicated by the XRD analysis (Fig. $\mathrm{S} 1$, Supporting Information). This dissolution of calcium carbonate is due to the low $\mathrm{pH}$ value (around $1.5)$ of the iron salt solution before the addition of $\mathrm{NaOH}$.

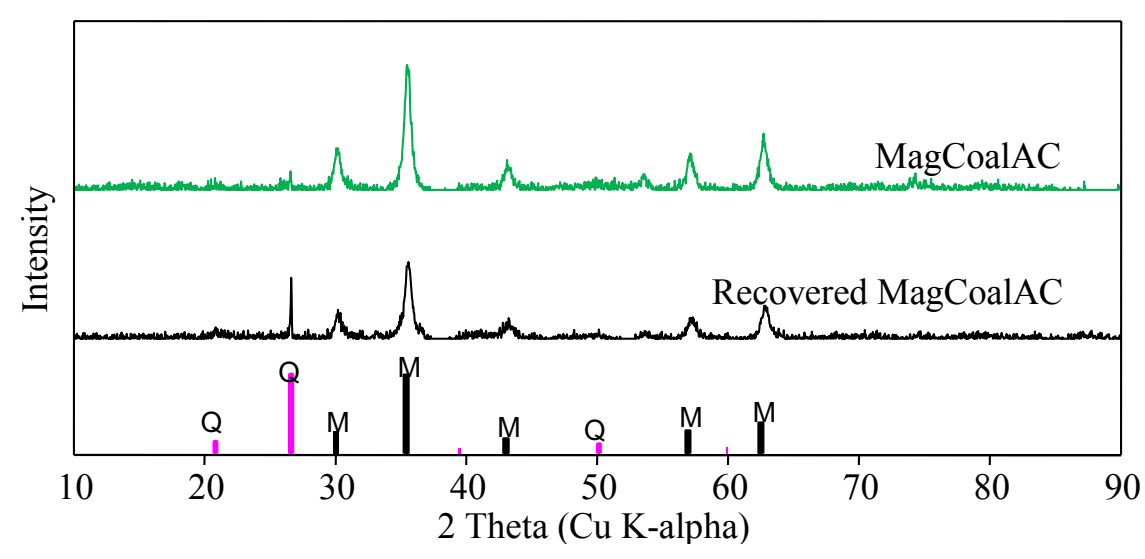

Fig.1 XRD patterns of the fresh MagCoalAC and recovered MagCoalAC. M: magnetite or maghemite; Q: quartz. 


\section{Table 1}

SSA and Logarithmic values of $K_{A C}(\mathrm{~L} / \mathrm{kg})$ sorbent-water distribution coefficients for selected PAHs on two $\mathrm{AC}$ and two $\mathrm{BC}$ materials and their magnetic equivalents.

\begin{tabular}{|c|c|c|c|c|c|c|c|}
\hline Sorbent & $\mathrm{SSA}\left(\mathrm{m}^{2} / \mathrm{g}\right)$ & $\begin{array}{l}\log K_{A C} \\
\text { anthracene }\end{array}$ & $\begin{array}{l}{ }^{*} \text { Normalized } \\
\text { Log } K_{A C} \\
\text { anthracene }\end{array}$ & $\begin{array}{l}\log K_{A C} \\
\text { pyrene }\end{array}$ & $\begin{array}{l}{ }^{*} \text { Normalized } \\
\text { Log } K_{A C} \\
\text { pyrene }\end{array}$ & $\begin{array}{l}\text { Log } K_{A C} \\
\text { chrysene }\end{array}$ & $\begin{array}{l}{ }^{*} \text { Normalized } \\
\text { Log } K_{A C} \\
\text { chrysene }\end{array}$ \\
\hline CoalAC & 974 & $6.6 \pm 0.1$ & & $7.1 \pm 0.2$ & & $7.5 \pm 0.2$ & \\
\hline MagCoalAC & 659 & $6.4 \pm 0.1$ & $6.6 \pm 0.1$ & $6.3 \pm 0.2$ & $6.5 \pm 0.2$ & $6.7 \pm 0.1$ & $6.9 \pm 0.1$ \\
\hline CocoAC & 975 & $6.5 \pm 0.2$ & & $6.8 \pm 0.3$ & & $7.4 \pm 0.3$ & \\
\hline MagCocoAC & $643 \pm 3.5$ & $6.5 \pm 0.2$ & $6.7 \pm 0.2$ & $6.5 \pm 0.2$ & $6.7 \pm 0.2$ & $6.9 \pm 0.2$ & $7.1 \pm 0.2$ \\
\hline Bio & 261 & $6.5 \pm 0.1$ & & $6.5 \pm 0.3$ & & $7.0 \pm 0.3$ & \\
\hline MagBio & $219 \pm 3.7$ & $6.2 \pm 0.3$ & $6.4 \pm 0.2$ & $6.0 \pm 0.3$ & $6.2 \pm 0.3$ & $6.6 \pm 0.2$ & $6.8 \pm 0.3$ \\
\hline OrgBio & $6.1 \pm 0.1$ & $5.6 \pm 0.3$ & & $5.4 \pm 0.4$ & & $6.3 \pm 0.5$ & \\
\hline MagOrgBio & $68 \pm 2.8$ & $5.8 \pm 0.4$ & $6.0 \pm 0.4$ & $5.6 \pm 0.4$ & $5.8 \pm 0.4$ & $6.4 \pm 0.5$ & $6.6 \pm 0.5$ \\
\hline
\end{tabular}

\subsection{Preliminary test results}

Activated carbon-water partitioning coefficients $\left(K_{A C}\right)$ determined in the sub to nanogram per liter free aqueous $\mathrm{PAH}$ concentration range using preloaded PE passive samplers for all the activated carbon material and magnetic carbon material demonstrated that OrgBio had lower $K_{A C}$ values than the other sorbents, as is illustrated for three PAH compounds in Table 1. MAC and MBC tended to have slightly lower $K_{A C}$ values than their respective pristine forms which can largely be explained by the lower carbon content, as iron oxide is unlikely to sorb PAHs. When normalized for the AC content, the sorption coefficient of the MACs is equivalent to that of the pristine AC for the small PAH compounds (i.e. anthracene in Table 1) and slightly reduced for the larger PAH compounds (i.e. chrysene in Table 1). Only MagOrgBio has slightly higher $K_{A C}$ than OrgBio, which may be due to the increase in the specific surface area of MagOrgBio $\left(68 \pm 2.8 \mathrm{~m}^{2} / \mathrm{g}\right)$ compared with OrgBio $(6.1$ $\pm 0.1 \mathrm{~m}^{2} / \mathrm{g}$ ). Overall, the data show how the PAH sorption capacity of the AC and biochar matrix is largely preserved in the magnetization process.

In a preliminary 30 day sediment remediation trial, all the pristine $\mathrm{AC}$ and $\mathrm{BC}$ amended batches showed significant decreases in the available PAH concentrations as measured by the uptake by PE samplers tumbled with the sediment ( $\mathrm{t}$-test, two-tailed, all $\mathrm{p}<0.05$ ). The sorbents abilities to reduce the PAH concentration in PE samplers follow the order of CocoAC $\approx$ CoalAC $>$ Bio $>$ OrgBio (Fig. 2), consistent with the trends in $K_{A C}$ values (Table 1). For the MAC and MBC, only MagCoalAC achieved a statistically significant reduction (t-test, two-tailed, $p<0.05$ ) in PAH concentrations in PE samplers in comparison with the control, and the apparent efficiencies (i.e. differences in the mean) followed the order of MagCoalAC $>$ MagCocoAC $>$ MagOrgBio $>$ MagBio.

The low short-term remediation efficiency of MAC and MBC in comparison with the original AC and biochar appears to be a kinetic effect, since their respective $K_{A C}$ values were comparable on a 
carbon-normalized basis (see Table 1). Slower PAH uptake by MAC and MBC could have been caused by the magnetite or maghemite deposits on the surface and in macropores of the impregnated sorbents which may slow down access to the most readily accessible sorption sites on the outer surface of the particles, and also increasing the tortuosity of the diffusion pathway into the microporous domain within the particle core, where most of the sorption capacity is located [33]. Based on these preliminary observations CoalAC and MagCoalAC were chosen as the most promising amendment materials for the longer term sediment remediation test.

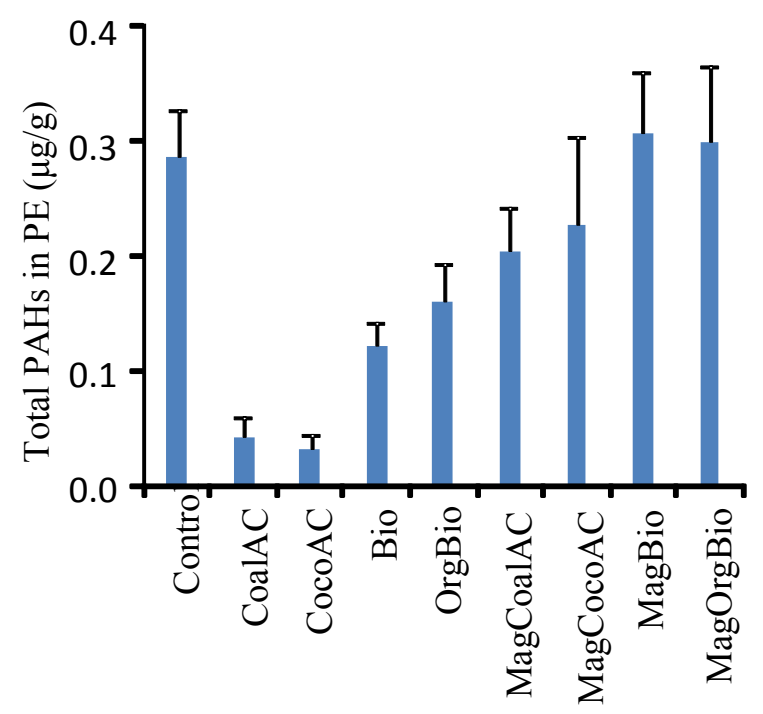

Fig.2 Total PAH concentrations in the PE samplers in River Wear sediment amended with different carbon materials.

\subsection{Magnetic sorbent recovery from sediment slurries}

MagCoalAC recoverability from the sediment was assessed with a magnetic rod after 3 months (Fig. 3). $6.010 \mathrm{~g}$ of magnetic matter was retrieved from the MagCoalAC amended River Tyne sediment, whereas $0.122 \mathrm{~g}$ of natural magnetic minerals was taken out from the unamended sediment. So the net weight of recovered MagCoalAC is $5.888 \mathrm{~g}$, or $77.0 \%$ of the initially added MagCoalAC mass. Recovery of the MagCoalAC with a magnetic rod was complicated by the fact that the rod attached particles had to be rinsed with a wash bottle to clean them from intertwined sediment. Loss of magnetism due to iron oxide dissolution could also explain the less than $100 \%$ recovery. But for the recovered MagCoalAC particles, XRD analysis confirmed magnetite or maghemite as the main iron oxide minerals with almost identical spectra to the pristine materials, except that some quartz signatures which were also present (Fig. 1). 


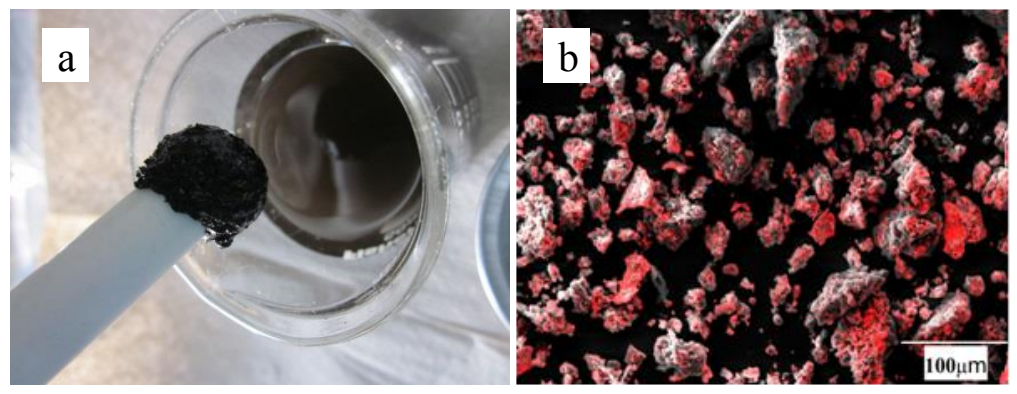

Fig.3 Recovery of the MagCoalAC with a magnetic rod (a) and the SEM-EDX image of the recovered MagCoalAC showing iron deposits in red (b).

\subsection{Solid phase PAH concentration}

The solid phase PAH concentrations in the River Tyne sediment were initially $16.9 \pm 0.6 \mathrm{mg} \mathrm{kg}^{-1}$ for the 16 US EPA PAHs and did not change significantly (fluorene, anthracene, and benz[a]anthracene, t-test, two-tailed, $\mathrm{p}<0.05$ initial vs. after 6 months), or decreased only slightly (naphthalene, acenaphthene, phenanthrene, fluoranthene, pyrene, chrysene, benzo[b]fluoranthene, benzo[k]fluoranthene, benzo[a]pyrene, benzo[ghi]perylene, indeno[1,2,3-cd]pyrene and dibenz[a,h]anthracene, t-test, two-tailed, $\mathrm{p}<0.05$ initial vs. after 6 months) in the unamended sediment during the remediation period (Fig. S2 in supporting information). This indicates the biodegradation of PAHs in the sediment is very slow. The low biodegradation rate is explained by the lack of desorption due to the high black carbon content of River Tyne sediment [22, 23].

The concentration of the high molecular weight PAHs ( 4 and 5 rings, $11.73 \mathrm{mg} \mathrm{kg}^{-1}$ ) is above the effects range median level $\left(9.6 \mathrm{mg} \mathrm{kg}^{-1}\right)$ of PAHs in sediment defined by the Centre for Environment, Fisheries and Aquaculture Science (CEFAS) of the United Kingdom government's Department for Environment, Food and Rural Affairs (Defra). These PAH concentrations are therefore potentially of concern, although there are currently no action level limits for PAHs in dredged material for possible disposal to sea in UK [34]. Hexane-acetone extractable total solid phase PAHs in CoalAC amended sediment, and MagCoalAC amended sediment following the $77 \%$ MagCoalAC recovery, were respectively $31 \%$ and $42 \%$ of the untreated sediment concentration after three months, and 9.6 and $16.2 \%$ of the untreated sediment after 6 months. It is well known that PAH extraction from AC amended sediment and soil is challenging due to the very strong sorption of PAHs by the AC or residual MAC matrix, which incidentally provides evidence for the greatly reduced $\mathrm{PAH}$ availability in the amended sediments [35].

\subsection{PAH concentrations in PE samplers}

After 3 months, total PAH concentrations in PE samplers of the unamended, CoalAC amended and MagCoalAC amended River Tyne sediment batches were 16.8, 0.27 and $0.41 \mathrm{ggg}^{-1}$, respectively (Fig. 4). This is equivalent to a statistically highly significant $98.5 \%$ and $97.6 \%$ reduction (t-test, two-tailed, $\mathrm{p}<0.01)$ in the PAH availability for CoalAC and MagCoalAC amended River Tyne sediment in comparison with the unamended sediment. This high reduction of PAHs uptake by PE is in good accordance with a previous study [23] which mixed 2\% CoalAC with particle sizes 63-125 $\mu$ m into the River Tyne sediment, and achieved 98\% reduction on PAHs uptake by PE samplers within 1 month. 


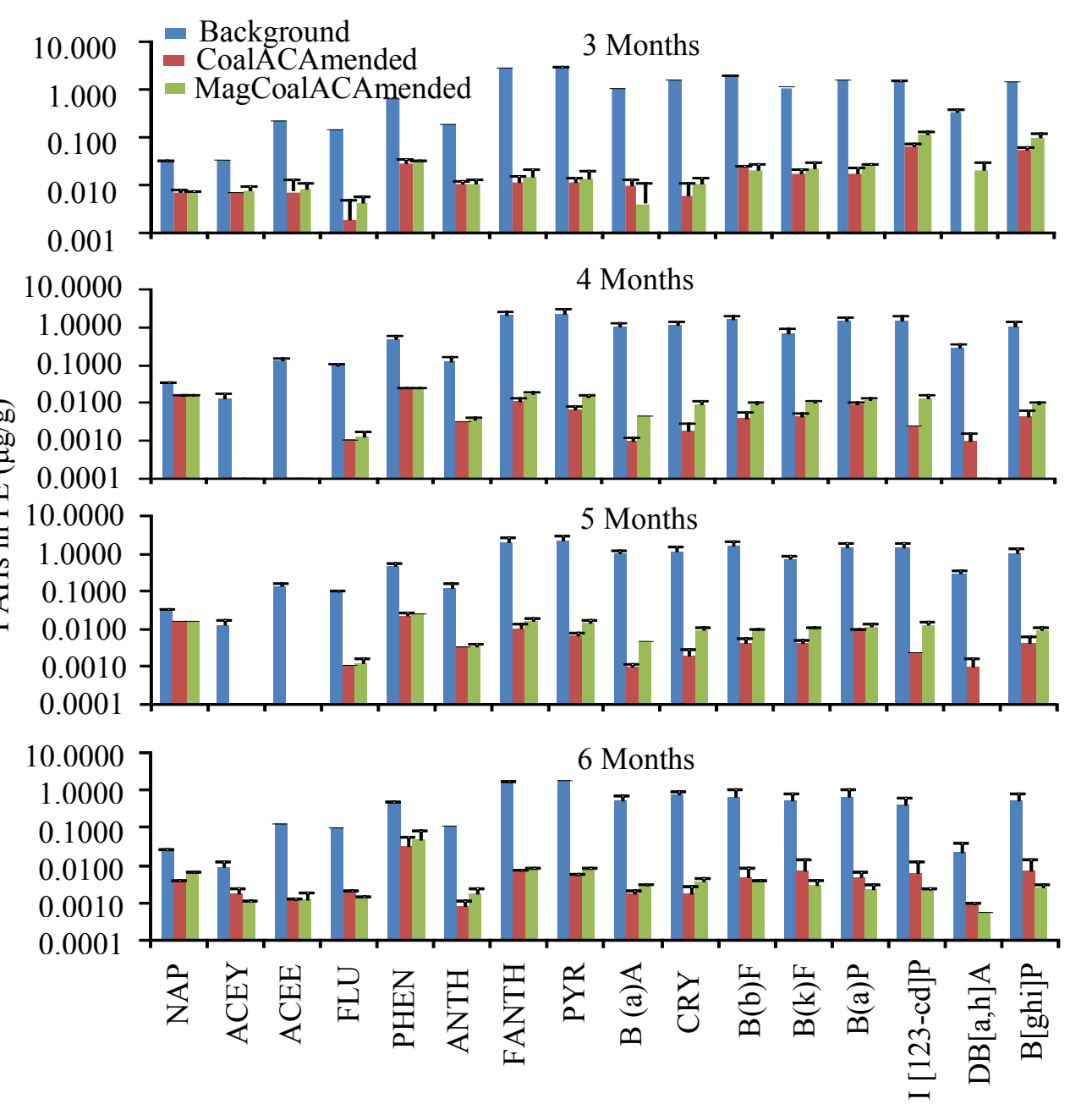

Fig. 4 Change of PAHs concentration in PE samplers in background, and CoalAC, MagCoalAC amended sediments. Error bars represent one standard deviation from three replicates. PAH abbreviations: NAP, naphthalene; ACEY, acenaphthylene; ACEE: acenaphthene; FLU, fluorene; PHEN, phenanthrene; ANTH, anthracene; FANTH, fluoranthene; PYR, pyrene; B[a]A, benz[a]anthracene; CHR, chrysene; $\mathrm{B}[\mathrm{b}] \mathrm{F}$, benzo[b]fluoranthene; $\mathrm{B}[\mathrm{k}] \mathrm{F}$, benzo[k]fluoranthene; $\mathrm{B}[\mathrm{a}] \mathrm{P}$, benzo[a]pyrene; I[1,2,3-cd]P, indeno[1,2,3-cd]pyrene; DB[a,h]A, dibenz[a,h]anthracene; B[ghi]P, benzo[ghi]perylene.

Similar nonmagnetic AC amendment benefits have also been demonstrated in other PAH polluted sediments $[17,36]$. Following the recovery of $77 \%$ of the added MAC after 3 months, the low PAH availability was maintained: With the exception of the 2 ring compound naphthalene which showed only a 50-70\% reduction, all the other PAH compound concentrations in PE samplers remained $97 \%$ to $99 \%$ lower in the CoalAC and MagCoalAC amended as compared to the unamended River Tyne sediment for the subsequent assessments at four, five and six months (i.e. one, two and three months after the 77\% MagCoalAC recovery) (Fig. 4). This indicates that either enough PAHs were removed with the recovered sorbent to maintain these benefits, or the $23 \%$ MagCoalAC residual was sufficient to keep PAH availability low, as also indicted by the low solvent extractability of the sediment 
associated PAHs mentioned above. A slight decrease in PAH availability over time (Fig. 4) was also observed in the unamended River Tyne sediment and can be explained either by PAH biodegradation of available PAHs [10] or the repeated removal of available PAHs with the PE samplers in a sediment with very slow PAH desorption.

\subsection{Ecotoxicity of the $A C$ amended and $M A C$ amended sediment}

The growth, reproduction, and egestion of Lumbriculus variegatus were strongly inhibited by the amendment of $5 \%$ CoalAC and also the $1.86 \%$ MagCoalAC amendment residual left in the sediment
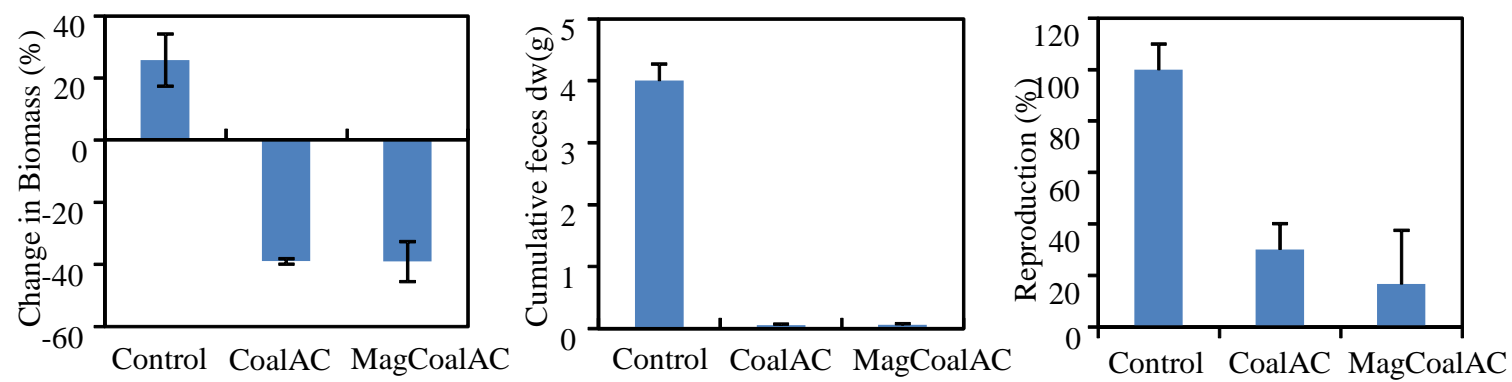

Fig.5 Lumbriculus variegates biomass change, cumulative feces, and reproduction in different $\mathrm{AC}$ treated sediment in 28 days.

after the magnetic recovery (t-test, two-tailed, all $p<0.05$, Fig. 5). All these phenomena indicate that the feeding of Lumbriculus variegatus was inhibited by the CoalAC or MagCoalAC amendment of the River Tyne sediment. As previously observed, addition of finely grained AC has negative ecotoxic effects on Lumbriculus variegatus in moderately contaminated sediments [15-17]. Disappointingly, the removal of $77 \%$ of the added MagCoalAC did not show any measurable benefits in terms of reducing the powdered $\mathrm{AC}$ ecotoxicity. This, though, is consistent with our previous study on the ecotoxicity of different size AC amended in sediment [16], in which a $0.5 \%$ powdered AC dose $(<63 \mu \mathrm{m}$, similar to the particle size of this study) in sediment, which is less than the residual MAC dose, already caused very strong inhibition on the egestion rate and growth of Lumbriculus variegatus. Perhaps the findings also indicate that the $\mathrm{AC}$ amendment effects are due to the sorption of essential nutrients rather than the presence of AC particles per se, in which case MAC recovery cannot alleviate the detrimental effects, as the MAC bound nutrients would be removed together with the recovered sorbent. Janssen et al. [37] suggested that sorption of food associated nutrients by the AC amendment was responsible for reduced Neanthes arenaceodentata growth in feeding studies.

\section{Conclusion and research needs}

This research demonstrated for the first time that i) MAC is almost as effective as pristine activated carbon in reducing aqueous PAHs in sediment; ii) MAC recovery from sediment after three months is feasible, but less than $100 \%$, and iii) the presence of unrecovered MAC maintains low aqueous PAH concentrations but has ecotoxic effects on the AC sensitive species Lumbriculus variegatus. Based on these results, there are several avenues for optimization of MAC based sediment remediation. Given the high effectiveness demonstrated in this study, the MAC dosage used could be reduced by about half to minimize unwanted side-effects. Furthermore, the mechanism of ecotoxicity should be investigated and compared for different magnetic activated carbons and also biochars, so that the selection of the most suitable sorbent material can take this important aspect into consideration, in addition to the sorbent's pollutant binding strength. Strategies for minimizing ecotoxic effects of MAC 
residuals such as nutrient amendment of treated sediment or the synthesis of magnetic sorbents with a slightly bigger particle size should also be explored. More work needs to be done to achieve effective recovery of the MAC under field conditions [38], for instance from sediment slurries with magnetic drums. MAC regeneration and re-use techniques [26] should also be investigated to bring down the costs of the MAC application, and the most suitable end-uses for the treated sediments [39] need to be identified.

\section{Acknowledgments}

Zhantao Han was supported by the Chinese Scholarship Council, a grant of the Royal Academy of Engineering (1314RECI002), a grant of China Geological Survey (12120113102700) and a grant of National Natural Science Foundation of China (41002088). Badruddeen Sani was supported by the Nigerian Petroleum Technology Development Fund. The ecotoxicity test was supported by Maj and Tor Nessling Foundation. Dr Martin Obst at the University of Tuebingen provided the SEM-EDX analysis.

\section{Supporting Information}

Details for the soil organic matter extraction, PAH extraction from PE samplers and analysis, XRD patterns of OrgBio and MagOrgBio, and changes of the sediment PAH concentrations in the remediation period are provided in supporting information.

\section{References}

[1] J.R. Zimmerman, U. Ghosh, R.N. Millward, T.S. Bridges, R.G. Luthy, Addition of carbon sorbents to reduce PCB and PAH bioavailability in marine sediments. Physicochemical tests., Environ. Sci. Technol., 38 (2004) 5458-5464.

[2] P.B. McLeod, M. J. Van Den Heuvel-Greve, R. M. Allen-King, S.N. Luoma, R.G. Luthy, Effects of Particulate Carbonaceous Matter on the Bioavailability of Benzo[a]pyrene and 2,2',5,5'Tetrachlorobiphenyl to the Calm, Macoma balthica, Environ. Sci. Technol., 38 (2004) 4549-4556.

[3] D. Werner, C.P. Higgins, R.G. Luthy, The sequestration of PCBs in Lake Hartwell sediment with activated carbon, Water Research, 39 (2005) 2105-2113.

[4] Y.M. Cho, U. Ghosh, A.J. Kennedy, A. Grossman, G. Ray, J.E. Tomaszewski, D.W. Smithenry, T.S. Bridges, R.G. Luthy, Field Application of Activated Carbon Amendment for In-Situ Stabilization of Polychlorinated Biphenyls in Marine Sediment, Environmental Science \& Technology, 43 (2009) 3815-3823.

[5] B. Beckingham, U. Ghosh, Field-Scale Reduction of PCB Bioavailability with Activated Carbon Amendment to River Sediments, Environmental Science \& Technology, 45 (2011) 10567-10574. [6] Y.-M. Cho, D. Werner, Y. Choi, R.G. Luthy, Long-term monitoring and modeling of the mass transfer of polychlorinated biphenyls in sediment following pilot-scale in-situ amendment with activated carbon, Journal of Contaminant Hydrology, 129-130 (2012) 25-37.

[7] S.E. Hale, P. Meynet, R.J. Davenport, D. Martin Jones, D. Werner, Changes in polycyclic aromatic hydrocarbon availability in River Tyne sediment following bioremediation treatments or activated carbon amendment, Water Research, 44 (2010) 4529-4536. 
[8] G. Cornelissen, M.E. Krusa, G.D. Breedveld, E. Eek, A.M.P. Oen, H.P.H. Arp, C. Raymond, G. Samuelsson, J.E. Hedman, O. Stokland, J.S. Gunnarsson, Remediation of Contaminated Marine Sediment Using Thin-Layer Capping with Activated Carbon-A Field Experiment in Trondheim Harbor, Norway, Environmental Science \& Technology, 45 (2011) 6110-6116.

[9] S.E. Hale, M. Elmquist, R. Brändli, T. Hartnik, L. Jakob, T. Henriksen, D. Werner, G. Cornelissen, Activated carbon amendment to sequester PAHs in contaminated soil: A lysimeter field trial, Chemosphere, 87 (2012) 177-184.

[10] P. Meynet, S.E. Hale, R.J. Davenport, G. Cornelissen, G.D. Breedveld, D. Werner, Effect of Activated Carbon Amendment on Bacterial Community Structure and Functions in a PAH Impacted Urban Soil, Environmental Science \& Technology, 46 (2012) 5057-5066.

[11] J.E. Tomaszewski, D. Werner, R.G. Luthy, Activated carbon amendment as a treatment for residual DDT in sediment from a superfund site in San Francisco Bay, Richmond, California, USA, Environmental Toxicology and Chemistry, 26 (2007) 2143-2150.

[12] U. Ghosh, R.G. Luthy, G. Cornelissen, D. Werner, C.A. Menzie, In-situ Sorbent Amendments: A New Direction in Contaminated Sediment Management, Environmental Science \& Technology, 45 (2011) 1163-1168.

[13] I. Hilber, T.D. Bucheli, ACTIVATED CARBON AMENDMENT TO REMEDIATE CONTAMINATED SEDIMENTS AND SOILS: A REVIEW, Glob. Nest. J., 12 (2010) 305-317. [14] M.I. Rakowska, D. Kupryianchyk, J. Harmsen, T. Grotenhuis, A.A. Koelmans, In situ remediation of contaminated sediments using carbonaceous materials, Environmental Toxicology and Chemistry, 31 (2012) 693-704.

[15] M.T.O. Jonker, M.P.W. Suijkerbuijk, H. Schmitt, T.L. Sinnige, Ecotoxicological Effects of Activated Carbon Addition to Sediments, Environmental Science \& Technology, 43 (2009) 59595966.

[16] I. Nybom, D. Werner, M.T. Leppänen, G. Siavalas, K. Christanis, H.K. Karapanagioti, J.V.K. Kukkonen, J. Akkanen, Responses of Lumbriculus variegatus to Activated Carbon Amendments in Uncontaminated Sediments, Environmental Science \& Technology, 46 (2012) 12895-12903.

[17] D. Kupryianchyk, E.P. Reichman, M.I. Rakowska, E.T.H.M. Peeters, J.T.C. Grotenhuis, A.A. Koelmans, Ecotoxicological Effects of Activated Carbon Amendments on Macroinvertebrates in Nonpolluted and Polluted Sediments, Environmental Science \& Technology, 45 (2011) 8567-8574. [18] E.M.-L. Janssen, B.A. Beckingham, Biological response to activated carbon amendments in sediment remediation, Environmental Science \& Technology, (2013).

[19] M.I. Rakowska, D. Kupryianchyk, M.P.J. Smit, A.A. Koelmans, J.T.C. Grotenhuis, H.H.M. Rijnaarts, Kinetics of hydrophobic organic contaminant extraction from sediment by granular activated carbon, Water Research, 51 (2014) 86-95.

[20] L. Jia, L. Xu, B. Gao, H. Gao, Remediation of DDTs-Contaminated Sediments through Retrievable Activated Carbon Fiber Felt, CLEAN - Soil, Air, Water, 42 (2014) 973-978. [21] J.R. Zimmerman, D. Werner, U. Ghosh, R.N. Millward, T.S. Bridges, R.G. Luthy, Effects of dose and particle size on activated carbon treatment to sequester polychlorinated biphenyls and polycyclic aromatic hydrocarbons in marine sediments., Environ. Toxicol. Chem., 24 (2005) 15941601. 
[22] D. Werner, U. Ghosh, R.G. Luthy, Modeling polychlorinated biphenyl mass transfer after amendment of contaminated sediment with activated carbon, Environ Sci Technol, 40 (2006) 4211 4218 .

[23] S.E. Hale, D. Werner, Modeling the mass transfer of hydrophobic organic pollutants in briefly and continuously mixed sediment after amendment with activated carbon, Environ. Sci. Technol., 44 (2010) 3381-3387.

[24] L.C.A. Oliveira, R.V.R.A. Rios, J.D. Fabris, V. Garg, K. Sapag, R.M. Lago, Activated carbon/iron oxide magnetic composites for the adsorption of contaminants in water, Carbon, 40 (2002) 2177-2183.

[25] B. Chen, Z. Chen, S. Lv, A novel magnetic biochar efficiently sorbs organic pollutants and phosphate, Bioresour. Technol., 102 (2011) 716-723.

[26] J. Gómez-Pastora, E. Bringas, I. Ortiz, Recent progress and future challenges on the use of high performance magnetic nano-adsorbents in environmental applications, Chemical Engineering Journal, 256 (2014) 187-204.

[27] G. Siavalas, D. Werner, H.K. Karapanagioti, B.F.J. Bowler, D.A.C. Manning, K. Christanis, Comparison of methods for the characterization and quantification of carbon forms in estuarine and marine sediments from coal mining regions, Organic Geochemistry, 59 (2013) 61-74.

[28] S. Hale, T. Martin, K.U. Goss, H. Arp, D. Werner, , Partitioning of organochlorine pesticides from water to polyethylene passive samplers, Environ. Pollut., 158 (2010) 2511-2517.

[29] Y. Choi, Y.-M. Cho, R.G. Luthy, Polyethylene-Water Partitioning Coefficients for Parent- and Alkylated-Polycyclic Aromatic Hydrocarbons and Polychlorinated Biphenyls, Environmental Science \& Technology, 47 (2013) 6943-6950.

[30] C.S. Castro, M.C. Guerreiro, M. Gonçalves, L.C.A. Oliveira, A.S. Anastácio, Activated carbon/iron oxide composites for the removal of atrazine from aqueous medium, Journal of Hazardous Materials, 164 (2009) 609-614.

[31] R.G. Adams, R. Lohmann, L.A. Fernandez, J.K. Macfarlane, P.M. Gschwend, Polyethylene devices: Passive samplers for measuring dissolved hydrophobic organic compounds in aquatic environments, Environmental Science \& Technology, 41 (2007) 1317-1323.

[32] M. Leppänen, J.K. Kukkonen, Factors affecting feeding rate, reproduction and growth of an oligochaete Lumbriculus variegatus (Müller), Hydrobiologia, 377 (1998) 183-194.

[33] S. Ahn, D. Werner, H.K. Karapanagioti, D.R. McGlothlin, R.N. Zare, R.G. Luthy, Phenanthrene and Pyrene Sorption and Intraparticle Diffusion in Polyoxymethylene, Coke, and Activated Carbon†, Environmental Science \& Technology, 39 (2005) 6516-6526.

[34] CEFAS, Monitoring of the quality of the marine environment, 2008-2010., in, 2010, pp. 111. [35] G.K. Vasilyeva, E.R. Strijakova, S.N. Nikolaeva, A.T. Lebedev, P.J. Shea, Dynamics of PCB removal and detoxification in historically contaminated soils amended with activated carbon, Environ. Pollut., 158 (2010) 770-777.

[36] R.C. Brändli, T. Hartnik, T. Henriksen, G. Cornelissen, Sorption of native polyaromatic hydrocarbons (PAH) to black carbon and amended activated carbon in soil, Chemosphere, 73 (2008) 1805-1810. 
[37] E.M.L. Janssen, Y. Choi, R.G. Luthy, Assessment of Nontoxic, Secondary Effects of Sorbent Amendment to Sediments on the Deposit-Feeding Organism Neanthes arenaceodentata, Environmental Science \& Technology, 46 (2012) 4134-4141.

[38] L. Chen, D. Xiong, Chapter Seven - Magnetic Techniques for Mineral Processing, in: S.

Tarleton (Ed.) Progress in Filtration and Separation, Academic Press, Oxford, 2015, pp. 287-324.

[39] I. Deibel, C. Lampe, J.P. Ulbricht, T. Cnudde, G. van Dessel, Beneficial Use, in: B. Giuseppe,

P. Leonardo (Eds.) Sustainable Management of Sediment Resources, Elsevier, 2007, pp. 119-132. 